and that almost immediately after her morning dose, which she took fasting, she was inspired with new life and energy. During the three years which she took the drug she made two attempts at giving it up, but she "felt so weak and ill and miserable, and suffered from such severe headache and vomiting," that she had to go back to the habit despite her resolution. Beginning with minute doses, she $n$ three years increased the dose to above eight grains of the acetate of morphia in the day. It all along caused constipation, for which she regularly took saline aperients, and she stated that it never made her dull or sleepy, although she could not sleep without it. During the last two years she had used belladonna in consequence of the action of the morphia on the pupils, and at periods of about three months she had suffered from severe bilious attacks accompanied by headache and the vomiting of bilious matter, which attacks she ascribed to the action of the morphia. She bought the morphia by the ounce, and "kept it in a bottle, taking her doses at all times by guess, and only taking a big dose when she felt that she needed it." She consumed an ounce every two months during the last year, "or in rather less time towards the end." On her showing me the bulk of her dose, it appeared a very good guess for five grains, and this dose she had taken morning (fasting) and evening (bedtime) daily. An ounce in two months gives eight grains a day for sixty days. On Sept. 17th she experienced for the first time pleasing and beautiful visions. These took the form of pictures, statuary, \&c., with vague but gorgeous surroundings; and some "power"-not voices-explained, or, rather, enabled her to appreciate, all their wonderful and strange beauty. These visions appeared while she walked or wandered in a pu alic park, and recurred on the following day, she having tak $\bullet \mathrm{n}$ a large dose of the morphia, and again sought the ma $_{c i c}$ shades of the park. This repetition of the increased dose and second wandering in the park point to a certain amount of volition in these visions, or at least to a total absence of any desire to shake off the strange but pleasing sensation. She was on this second day picked up in a dazed or stupid state, and on a bottle labeled "morphia" being found in her pocket, she was first charged with attempting sulcide, but afterwards was certified as insane and sent to an asylum. From this time (Sept. 18th) she had no morphia or other hypnotic or sedative except on the evening of the tenth day, when she had a draught containing fifteen grains of chloral and thirty grains of bromide of potassium. The symptoms appearing after the discontinuance of the drug were, with the exception of hyper-sensitiveness of the skin, which was not noticed, almost identical with those so minutely noted by Dr. S. J. Sharkey in the record of his case which appeared in THE LANCET of Dec. 29 th last, and need not here be repeated. She was at first restless and sleepless, suffering much from a feeling of extreme weakness, frequent vomiting, headache, severe burning pain in the stomach, complete anorexia, constant but not alarming diarrhœa, and rather profuse general sweating; hiccough was not very troublesome, but was noticed by the patient. A mixture of carbonate of bismuth with ginger and orange was ordered, which quieted the stomach considerably. The appetite was on the sixth day fairly good, and soon became very sharp. The diarrhcea continued in a mitigated form for over sixteen days, and gradually disappeared. She improved daily, and in thirty days gained twenty-three pounds in weight. Mentally she was on admission suffering from a low form of mania bordering on dementia ; in fact, her mind and body were in much the same state-viz., extreme general debility. She had delusions of a vague character at first, but these disappeared in a few days and left her mind quiet but very weak. She was listless, dull, and apathetic in the extreme, of ten cried, but had occasional short periods of exaltation. Finally, with regard to the truthfulness of her statements, I found she was, to put it mildly, most inaccurate in many things, although on other subjects she spoke truthfully and honestly. There did not seem to be any aim or end in view to account for these perversions of fact, yet it was noticed that many of these tales tended rather to show her own superiority mentally, socially, and otherwise.

The patient was discharged from the asylum on Oct. 30th, apparently recovered, looking infinitely better than on admis sion, eating and sleeping well, and with no desire, she said, for a renewal of the morphia eating.

Whether she relapsed I cannot say, as I have not since been able to discover her whereabouts.

Northampton.
THE

\section{SUBCUTANEOUS INJECTION OF MORPHIA.}

BY C. EGERTON JENNINGS, L.R.C.P. LOND.,

ASSISTANT-DEMONSTRATOR OF ANATOMY IN THE UNIVERSITY OP DURHAME COLLEGE OF MEDICINE.

BARTHOLOW writes with much earnestness ${ }^{1}$ on the superiority of extemporaneous over permanent solations of the alkaloids for hypodermatic medication, and he adduces a powerful argument against those of the latter characterviz., their rapid tendency to deteriorate from the develop. ment of the penicillium, which grows partly at the expense of the alkaloids, and hence whilst such solutions increase in turbidity they decline in power. But there is a still more cogent reason against the employment of permanent solutions of morphia. Everyone is aware that apomorphia, which is a speedy emetic, even in minute doses, differs only in formula from morphia in containing a molecule less of $\mathrm{H}_{2} \mathrm{O}$, and whilst many practitioners bave been disagreeably surprised by the prompt emesis consequent on the sub. cutaneous injection of "morphia," few actually realise the fact that morphia, kept in solution for some weeks, de. composes and yields apomorphia. In order to prove chemi. cally the point at issue, which is unfortunately every day being illustrated physiologically, I have, with the kind assistance of Professor Bedson, recently conducted a series of experiments on various preparations of morphia, apo. morphia, and their salts. Nitric acid and perchloride of iron, excellent reagents though they be for discriminating between morphia and apomorphia when separate, are quite valueless for detecting traces of the one when mixed with comparatively large quantity of the other. Solutions, even the most dilute, of apomorphia and its salts, on being boiled

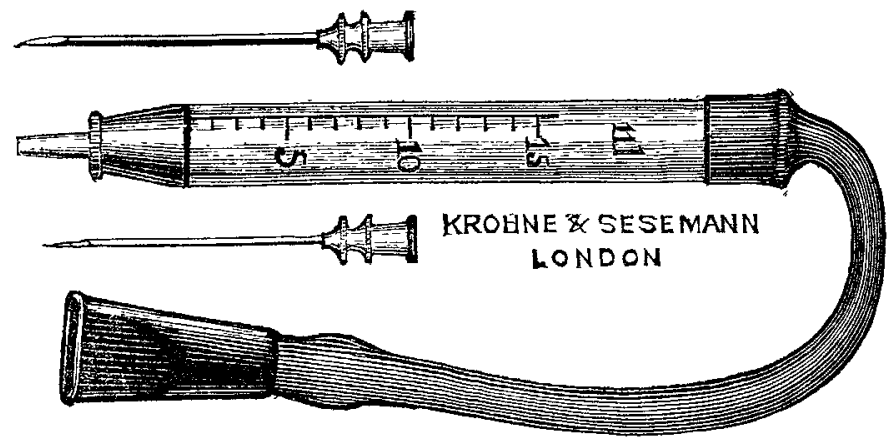

with excess of caustic potash, oxidise rapidly and turn brown, whilst solutions of morphia do not, and this appears to be the crucial test for traces of apomorpbia in the presence of morphia. Less than $\frac{1}{5}$ th of a grain of apomorphia can be detected by this method, and the examination of solutions of morphia, of ages ranging between two months and two years, has demonstrated apomorphia in all, the impurity existing in relatively larger quantity in the older and more discoloured specimens, which are notoriously those especially prone to excite vomiting, and therefore certainly unfit for subcutaneous administration. The practical outcome is obvious. In hospital practice, where the consumption of morphia is large, "permanent" solutions may be used freely, since they are in reality "extemporaneous." But in private practice the case is different. Here hypodermatic medication is often not resorted to for weeks together, and the use of extemporaneous solutions is loudly called for. On this con sideration I have obtained sa mples of sulphate and bimeconate of morphia, in the form of Wyeth's compressed tablets, prepared about three months ago. None of the solutions of these tablets, on being boiled with caustic potash, and subsequently agitated with air, turned brown.

The condition of the syringe employed for the operation plays a very important rôle in the success of a subcutaneous injection. Though the instrument be periodically inspected by its maker, and the washer frequently anointed and often renewed, so that the piston shall slide properly within the barrel, the syringe is still not irreproach. able, for contact of the medicated solution with a greasy piston is surely most objectionable. Recently complaints have appeared in the journals against what is by no means a necessary evil, and a simple means of obviating the diff. culty might be found in the adoption of a suitable pipette,

1 A Manual of Hypodermatic Medication, fourth edition, p. 30 , et seq 
such as that shown, on a reduced scale, in the above engraving. The pipette is graduated in minims, the gradations being three-sixteenths of an inch apart. If longer intervals be needed to ensure very accurate dosage, a tube of smaller calibre should be employed. In charging the instrument more of the medicament must be taken up than is required for injection in order to avoid the possibility of injecting air after the solution. This pipette cannot become disordered like the syringe, since it has no piston, and its cost is trifling.

Nowcastle.

\section{ON THE}

\section{YELLOW PIGMENTS FOUND IN THE VISCERA} IN CASES OF ARSENICAL POISONING.

\section{By THOMAS STEVENSON, M.D.}

IN an interesting communication on the above subject in THE LANCET of the 8th inst., p. 421, Dr. Campbell Brown and Mr. Davies record their examination of a bright-yellow pigment met with in three bodies exhumed after death from arsenical poisoning, and conclude that the pigment resembled one of the products of decomposition of bile pigment. They moreover state that "no proof has ever been adduced, so far as we are aware, that the yellow substance observed in such cases is really sulphide of arsenic." This novel and valuable observation is in accord with what is known of the occasional yellow discharges from the bowels during the course of cases of arsenical poisoning referred to in Dr. A. S. Taylor's " Principles and Practice of Medical Jurisprudence" (third edition, edited by myself, vol, i., p. 257), where it is stated that "the matters discharged from the stomach and bowels have had in some instances a yellowish colour, as it was supposed, from a partial conversion of the poison into sulphide, but more probably from an admixture of bile." The authors of the paper referred to go too far, however, when they assert that no proof has been adduced that the yellow substance met with in exhumed bodies is sulphide of arsenic. Christison ("Poisons") in speaking of the solid particles of arsenic found in the stomach, mentions the brilliant yellowness of the surface of these particles, and adduces four cases of this character which came under his own notice, and adds that in all these he found the oxide as well as the sulphuret of arsenic. In one of these cases, besides the oxide and sulphide, he found sulphuretted hydrogen gas in the stomach. In the case of Margaret Warden, yellow arsenical solid particles floated in the stomach fluids. In the case of Reg. $v$. Jennings (Berkshire Lent Assizes, 1845) Taylor describes how he, in an exhumation case, obtained abundant evidence of the arsenical nature of the yellow substance by means of several reactions, which are given in detail (Guy's Hospital Reports for 1845, p. 187). In another case, Reg. $v$. Garner and Garner, tried at Lincoln in 1863, Dr. Taylor found in a case of exhumation arsenic "partly in a soluble, and partly in an insoluble form, that is, as orpiment or yellow arsenic," the quantity of which he puts as six or eight grains. ${ }^{1}$ I well remember seeing these powdery masses of yellow arsenic in one of Dr. Taylor's cases To these I may add an observation of my own, on the body of Elizabeth Kittle, exhumed in 1872, six months after burial (Reg. v. Kittle, Chelmsford Summer and Autumn Assizes, 1872), where there was extensive yellow staining of the stomach, orange-coloured staining of the duodenum, and also a considerable amount of solid yellow matter in the stomach, gritty to the touch. The yellow portion of this was insoluble in water and could be seen coating the surface of fragments of white arsenic. The yellow matter was conclusively proved by chemical tests to be sulphide of arsenic.

I think there can be no doubt that gritty yellow sulphide of arsenic is not very rarely formed from arsenious oxide in the viscera after death; but this must not be confounded with the yellow substance described by Dr. Brown and Mr. Ddvies. Guy's Hospital.

1 Pharm. Jour., 1862-3, p. 377.

THE West Hartlepool Improvement Commissioners have purchased an ambulance van, and the members of the St. John Ambulance Association in that town have been instructed as to its us:
MIXED SARCOMA, ORIGINATING IN THE PERIOSTEUM OF THE CLAVIULE,

ATTENDED WITH PYREXIA; DEATH； NECROPSY.

BY CHAS. I. SANSOM, M.R.C.S.

HOUSE-PHYSICIAN TO THE ROYAL FREE HOSPITAL.

GEORGE E-, aged forty, a farrier, was almitted iuto the Wynn Ellis ward, Royal Free Hospital, under the care of Dr. Cockle, on November 5th, 1883.

Previous history.-The patient states that he had small-p $n x$ fourteen years ago, but gives no account of any other illness. There is no history of any hereditary disease in the family. His father and mother both lived to a great age ; his brothers, sisters, and his own children are healihy.

History of present illness. - He dates his attack five months back, when he noticed that his right shoulder began to s well, followed fourteen days afterwards by swelling of his right arm, causing him great pain. The enlargement about innll around the shoulder increased until admission, causing slingt dysphagia and hoarseness.

Condition on admission.-He is a well. built mar, but bas the appearance of intense suffering, with his head drawn slightly towards the right side and his right arm supported with the left. Skin perspiring freely; right pupil contracted. On examining the neck (on the right side) a hard mass is felt, extending from a point midway between the pinna of the ear and the mastoid process of the temporal bone, backwards to the superior border of the scapula, and downwards into the axilla, effacing the outline of the clavicle in its middle third, and inwards, displacing the trachea a lit tle to the left. Brawny induration extends from the neck, down the right arm and side as far as the iliac crest ; tongue coated with a thick white fur; bowels constipated ; slight dysphagia ; heart and lung sounds normal; pulse 100 , weak and compressible ; temperature $104 \cdot 6^{\circ}$; urine, sp. gr. 1020, containing one-sixth albumen. Ordered milk diet, bellad onna liniment to be painted over the swelling, and the following mixture: Tartarated antimony, one twenty-fourth of a grain; solution of acetate of ammonia, half a drachm; tincture of aconite, two minims ; camphor water to one ounce; to be taken three times a day.-Nov. 7th : No rest last night, complains of great pain in right arm; pulse 130, weaker; morning temperature $103 \cdot 2^{\circ}$, evening $102 \cdot 8^{\circ},-9$ th : Looks much worse; voice almost gone. Pulse 130 ; morning temperature $100.2^{\circ}$, evening $1024^{\circ}$; diaphoresis continues. Ordered quinine in two-grain doses every four hours.-10th : Much weaker; pulse 130 ; morning temperature $1048^{\circ}$, evening $103^{\circ}$. Dyspnœea gradually increasing in severity; urine and freces passed involuntarily; is conscious, but cannot articulate.-11th, 1 A.M. : Temperature $105 \cdot 6^{\circ}$; sinking rapidly; died at $1.30 \mathrm{~A} . \mathrm{M}$.

Autopsy, twenty eight hours after death. - Rigor mortis well marked. Thorax : Lungs slightly odematous and congested; an old pleuritic adhesion, about the size of half a crown, on the right side. Heart thin-walled and very friable, but no valvular mischief present. Abdomen: Liver fatty; weight $50 \mathrm{oz}$ Spleen large and soft Left kidney: Capsule stripped easily. Superficial cortical veins congested, but substance of cortex not diminished in size. A small mass of firm consistence, about the size of a walnut, was observed extending from the cortex inwards. Right kidney normal. On examining the neck, a hard firm mass was found projecting from the middle third of the clavicle, extending upwards to the angle of the lower jaw, backwards to the superior border of the scapula, inwards to the longus colli muscle, displacing the trachea and cesophagus to the left side, and implicating the lower cervical and ifrst dorsal nerves; below, it was continuous with the infiltrated axillary glands, and adherent to the skin along the upper border of the trapezius muscle. Upon removal of the mass, which was not encapsuled, it presented a white appearance, was of hard consistence, and arose from the periosteum of the middle third of the clavicle, the bone itself being healthy; it completely surrounded the subclavian artery, without diminish. ing its calibre. Brain healthy. The brawny swelling down the arm and side showed no new growth, but was probably the result of lymphatic and venous obstruction. Microscopical examination showed the tumour to be a mixed sareoma, small round cells largely preponderating. There were several deposits of sarcoma in the kidney. 